This item was submitted to Loughborough's Research Repository by the author.

Items in Figshare are protected by copyright, with all rights reserved, unless otherwise indicated.

\title{
Factors associated with chest injuries to front seat occupants in frontal impacts
}

PLEASE CITE THE PUBLISHED VERSION

https://doi.org/10.1080/15389588.2019.1654606

PUBLISHER

Taylor \& Francis

VERSION

AM (Accepted Manuscript)

PUBLISHER STATEMENT

This is an Accepted Manuscript of an article published by Taylor \& Francis in Traffic Injury Prevention on 2 October 2019, available online: http://www.tandfonline.com/10.1080/15389588.2019.1654606.

\section{LICENCE}

CC BY-NC-ND 4.0

\section{REPOSITORY RECORD}

Ekambaram, Karthikeyan, Richard Frampton, and James Lenard. 2019. "Factors Associated with Chest Injuries to Front Seat Occupants in Frontal Impacts". Loughborough University.

https://hdl.handle.net/2134/38353. 


\title{
Factors Associated with Chest Injuries to Front Seat Occupants in Frontal Impacts
}

\author{
*Karthikeyan Ekambaram, **Richard Frampton, **James Lenard \\ *Institute for Future Transport and Cities, Coventry University, UK \\ **Loughborough Design School, Loughborough University, UK
}

Correspondence: Dr Karthikeyan Ekambaram, Institute for Future Transport and Cities, Coventry University, Coventry, UK, CV1 2TE

Email Address: karthikeyan.ekambaram@coventry.ac.uk

\begin{abstract}
Objective: Improving crash protection for older car occupants is a matter of urgency since the number of older car users is forecast to grow dramatically over the next two decades. The thorax is particularly vulnerable in older occupants, and this study aimed to provide real-world in-depth analysis of factors contributing to chest injuries in frontal impacts involving European cars.
\end{abstract}

Methods: Real world crash injury data were interrogated, focusing on cars with current restraint components. The research examined belted front-seat occupants in frontal impacts where air bags, pretensioners and load limiters were present.

Results: The chest was the most often injured body region at AIS 2+, 3+ and 4+ injury levels. The rate of AIS 2+ and AIS 3+ chest injuries was highest among elderly occupants and lowest among young occupants, and elderly occupants sustained proportionally more severe chest injuries in low/moderate speed impacts compared to young and middle-aged occupants. However, it should be noted that rates of AIS 2 chest injury were also significantly higher for middle-aged occupants compared to the young. The front passenger seat was shown to be more often associated with significant chest injury than the driver seat. The higher proportion of elderly female occupants was postulated as a reason for this. Skeletal injury was the most frequent type of AIS 2+ chest injury and the rate of injury for elderly occupants with such injuries was higher than for young and middle-aged occupants. With the increase in the number of rib fractures, the risk of pulmonary complications and organ injuries tended to increase. The major cause of chest injury was identified as restraining loads transmitted to the chest via the seat belt. The absence of intrusion in the majority of cases, suggests an opportunity for the restraint system to better manage the crash pulse. Not only for elderly occupants but for those who are middle-aged as well.

Conclusions: This study shows the necessity for safety interventions, through new vehicle crashworthiness systems to improve chest protection especially for middle aged and elderly car occupants. Deployment of appropriate injury risk criteria, use of an appropriate dummy thorax, development of a low energy restraint test, and the development of more adaptive restraints have been discussed as possible solutions to the problem.

Keywords: Real world crash, Chest injury, Older Occupants, Accident Analysis, Crash Tests 


\section{INTRODUCTION}

There is now a recognition of major shifts in the population age distribution in most motorised countries. The number of older people in the European Union is projected to grow dramatically over the next two decades and beyond (Zaidi 2008). It is predicted that by 2050, the proportion of older people (65 years and above) in Europe will be close to 30\%. In the US by 2030, 19\% of the population will be aged 65 or over (Ridella et al. 2012). Similarly, in Australia the proportion of older persons aged above 65 years is projected to rise to $24.2 \%$ by 2051 (Australian Bureau of Statistics 2006).

Mobility is a critical factor to carry out life's activities and in most western countries, private passenger cars satisfy this need (Oxley et al. 2010). As their populations grow, it is expected that the number of older people using passenger cars will be greater than ever before. In the UK, more than 4 million adults above 70 years old are currently licensed. It is predicted that 40 million older adults (65 years and above) will be licensed in the US by the year 2020, compared to 19.9 million in 2002 (Dellinger et al. 2002).

In addition, it is generally acknowledged that age is an important determining factor of injury outcome in a vehicle crash. The European road safety report (DaCoTA 2011) shows that in the year 2009, almost 7000 elderly people (>64 years old) died in European road traffic accidents, accounting for more than one-fifth of the total fatalities. Older occupants differ from young or middle age occupants in several respects including physiological tolerance, injury outcomes and crash exposures (Islam \& Mannering 2006; Kent et al. 2009). Previous studies have shown that biomechanical tolerance to loading declines with age, so that a greater level of injury is sustained for a given magnitude of loading (Augenstein 2001; Welsh, Morris, Hassan, et al. 2006; Dejeammes \& Ramet 1996; Kent et al. 2008). Additionally, older people are more frail than younger, so they tend to have worse outcomes for the same injury (Kent et al. 2009). These findings have significant implications for the crash injury protection of older occupants. Real world crash injury studies were identifying older occupant protection issues some 25 years ago. For example, Frampton and Mackay (1994) highlighted the elevated risk of chest injury for older front seat occupants in frontal impacts involving European cars. The vehicles in that study would have been required to pass ECE R12 which specified a $50 \mathrm{~km} / \mathrm{h}$ impact into a full width rigid barrier, with a limit on steering column rearward movement. Since then, more stringent crash test requirements have been introduced in Europe. ECE R94 was introduced in 1996 for new model vehicles and 2003 for all vehicles. It involves a frontal offset impact into a deformable barrier at $56 \mathrm{~km} / \mathrm{h}$ and is currently the only legally required frontal impact procedure, although the similar, but higher severity EuroNCAP test has been a major driver in frontal impact safety. These tests resulted in not only the rapid adoption of better (more rigid) frontal structures, but also the introduction of frontal airbags, seat belt pretensioners and load limiters the restraints that cars are universally fitted with today. In an early study of R94 compliant cars, Kirk et al (2002) showed that the new design changes appeared to have very positive effects for head protection but there was a question mark concerning improvements to chest protection. In light of the forecasts for greater numbers of older car users, this study proposed to examine the factors associated with chest injury in real frontal impacts involving cars complying with ECE R94.

\section{METHODS}

UK Co-operative Crash Injury Study (CCIS) 
CCIS data collected between 2000 and 2010 were used for the most part in this study, and vehicles were selected which contained frontal airbags, pretensioners and load limiters. This ensured a large sample of vehicles which had complied with Regulation 94 and many of which had also been put through EuroNCAP testing. CCIS collected in-depth crash and injury information from selected geographical regions representing urban and rural roads in Great Britain. The sampling methodology is described by Mackay et al. (1985) and Hassan et al. (1995). The sampling prescribed passenger cars, less than 7 years old, with at least one injured occupant and towed away from the crash scene. The database contained detailed information on vehicle crash severity, estimated by the Equivalent Energy Speed (EES), structural performance and restraint performance together with photographic documentation of the vehicle exterior and interior. Occupant injury mechanisms were deduced by the case investigators based on forensic evidence in each vehicle and an assessment of occupant kinematics. The EES was evaluated on the assumption that the vehicle deformation was caused by an impact with a rigid, immovable object (Lenard, Hurley, et al. 1998). Injury outcome was recorded using the Abbreviated Injury Scale AIS 90, (Association for the Advancement of Automotive Medicine 1990). Additional injury coding using AIS 2005 (Association for the Advancement of Automotive Medicine 2005) was added in the latter stages of the study, but was only available for a limited number of cases. AIS 90 was available for all cases and was therefore chosen as the injury scale for analysis. Weighting factors were applied to the data, based on police recorded accident severity, in order to allow analysis of a representative sample of crashes.

The subsequent criteria used to select the frontal impact population are shown below:

- $\quad$ Single frontal crash or 2 impacts with frontal impact being the most significant in causing injuries.

- $\quad$ No underride or rollover crashes.

- $\quad$ Principal direction of force between $-30^{0}$ and $+30^{0}$.

- $\quad$ Three-point belted front seat occupant $\geq 15$ years of age.

The unweighted accident sample consisted of 1,782 front seat occupants. Applying weighting factors gave 5,234 front seat occupants consisting of 4,301 (82\%) drivers and 933 (18\%) front seat passengers (FSP). For all statistical tests, the significance level was set at a 95\% confidence level $(\mathrm{p}<0.05)$. The occupant age was broadly categorised into three groups: a) young: 15-39 years, middle-aged: 40-64 years and c) elderly: 65+ years. This classification was based on that used in previous European real world accident studies (Welsh, Morris, Hassan, et al. 2006; Morris, et al. 2003).

\section{UK Road Accident In-depth Studies (RAIDS)}

This UK in-depth crash injury study replaced the CCIS programme in 2012 but collects compatible information, using the Abbreviated Injury Scale AIS 2005, (Association for the Advancement of Automotive Medicine 2005) for injury classification. Data collected between 2013 and 2018 were interrogated in the same way as for the CCIS data, but a smaller overall sample size restricted many of the proposed analyses once additional data queries were applied. The unweighted accident sample consisted of just 309 front seat occupants. Therefore, the analysis presented in this paper primarily concerns the larger CCIS dataset, although it was possible to obtain some limited results from the RAIDS data, and this is flagged when it is presented. 


\section{RESULTS}

\section{General Sample Characteristics}

Occupant age: More than half of all occupants (52\%) were aged between 15 and 39 (young), 35\% were aged between 40 and 64 (middle-aged) and 13\% were aged over 64 (elderly). The proportion of elderly occupants in the front passenger seat (18\%) was greater than in the driver seat (12\%). The mean ages of drivers and front passengers were significantly different when compared using an Independent Samples T-test $(\mathrm{p}<0.05)$.

Occupant gender: Overall, 58\% $(n=3033)$ of occupants were male and $42 \%(n=2201)$ were female. The majority of drivers were male (63\%), while the majority of front seat passengers were female (67\%).

Crash severity by seating position: The distribution of crash severity was very similar between the two front seat occupant groups (Figure A 1, Appendix). The majority (69\%) of impacts occurred between 20 and $45 \mathrm{~km} / \mathrm{h}$. The EES for $97 \%$ of all impacts was below $50 \mathrm{~km} / \mathrm{h}$ and $99 \%$ occurred below $60 \mathrm{~km} / \mathrm{h}$. Therefore, most impacts did not exceed the crash severity of European frontal test requirements.

Crash severity by seating position and age: The mean crash severity (EES) was compared between age groups in each seating position. No significant differences were found for EES exposure between each age group in each seating position ( $\mathrm{p}>0.05$ ) (Table A 1 , Appendix).

Facia intrusion: Of all occupants, 91\% experienced intrusion below $3 \mathrm{~cm}, 4 \%$ had sustained intrusion between 3 and $9 \mathrm{~cm}$, and $4 \%$ sustained intrusion greater than $10 \mathrm{~cm}$. Intrusion was not known for 1\% of the sample. The overall implication is that intrusion was well controlled in the sample of cars.

Maximum Abbreviated Injury Severity (MAIS) by seating position: The MAIS represents the overall injury severity to an occupant. The proportions of front seat passengers with MAIS 2 (16.7\%) and MAIS 3+ (6.2\%) injury were greater than those for drivers MAIS 2 (9.8\%), MAIS 3+ (5.0\%) (Table A 2, Appendix). The Chi Squared test showed a significant relationship between injury severity outcomes and front seating positions $(\chi 2$ $=42.192$, d.f $=2, \mathrm{p}<0.05)$.

MAIS by age: Older occupants were over-represented at all levels of injury severity from MAIS 2 and above. The injury risk to middle-aged occupants from MAIS 2 and above was also greater than for young occupants (Figure A 2, Appendix). 29\% of the older occupants had MAIS 2+ level injury compared to 18\% of middle aged and $12 \%$ of younger occupants. A Chi Squared test found that the distributions of injury severity across the three age groups were significantly different $(\chi 2=186.75$, d.f $=12$, $\mathrm{p}<0.05)$.

MAIS by body region: Table 1 shows the rate of AIS 2+, 3+ and 4+ injury by body region, for all occupants. Injuries to the head at the AIS $2+$ level were received by $1.9 \%$ of occupants. Only $1.1 \%$ of occupants had neck injury at the AIS 2+ level. The chest was the most frequently injured body region at all AIS severity levels. 6.5\% of all occupants sustained AIS 2+ chest injury, while 2.3\% of all occupants had sustained AIS 2+ abdominal injury. The second most frequently injured body region at the AIS 2+ level was the upper extremity (6.3\%) followed by the lower extremity (5.1\%). None of the injuries to the extremities were rated at AIS 4 or above. 


\section{Chest Injury}

Chest injury severity rate by seating position: 244 drivers and 94 front seat passengers sustained chest injuries at the AIS 2+ level. The rate of chest injury for front seat passengers was higher than for drivers at AIS $1+, 2+$ and $3+$ levels. The rates of AIS 2+ and 3+ chest injury for the front seat passenger were $10 \%$ and $4 \%$ respectively. Those rates were 1.7 times higher than for drivers at the AIS 2+ level and twice as high as drivers at AIS 3+ (Figure A 3, Appendix).

Chest injury severity rate by age: Figure 1 shows the rate of AIS 2+ and AIS 3+ chest injury for occupants by age group. The rate of injury at both severity levels increased with the age. The rate of AIS 2+ injury for younger, middle-aged and older occupants was 2\% ( $n=55), 9 \%(n=169)$ and 16\% ( $n=114)$ respectively. 1\% of younger occupants ( $n=33)$, 3\% of middle-aged occupants $(n=47)$ and $8 \%$ of elderly occupants $(n=54)$ had sustained at least one AIS 3+ chest injury. Elderly occupants had much higher rates of both AIS 2+ and AIS 3+ injury compared to young and middle-aged occupants. Of particular note is the much higher rate of AIS 2+ chest injury for middle aged occupants compared to the young. Though a comparison of the AIS 3+ injury rates suggest that the major difference between young and middle-aged occupants is due to the latter's higher susceptibility to AIS 2 chest injury.

Crash severity of chest injured occupants by age: 160 (47\%) of all AIS 2+ chest injured occupants had sustained their injury with EES less than $30 \mathrm{~km} / \mathrm{h}$ and 75\% below $40 \mathrm{~km} / \mathrm{h}$. The rate of AIS 2+ chest injury at EES less than $30 \mathrm{~km} / \mathrm{h}$ was $0 \%, 7 \%$ and $13 \%$ for younger, middle-aged and elderly occupants respectively. Considering EES above $50 \mathrm{~km} / \mathrm{h}$, the rate of AIS 2+ chest injury to younger, middle-aged and elderly occupants were $24 \%, 37 \%$ and $53 \%$ respectively.

The mean EES for AIS 2+ and 3+ chest injured occupants by age is shown in Table 2. It shows that crash speeds were generally higher with higher injury severity. However, the mean EES for AIS 2+ chest injured elderly front seat occupants (30.8 km/h) was less than that for young (45.2 km/h) and middle aged (32.1 km/h) occupants. Similarly, the mean EES of AIS 3+ chest injured elderly occupants (36.0 km/h) was less than for young (49.9 km/h) and middle-aged (42.6 km/h) occupants. One-way analysis of variance (ANOVA) tests found a significant difference in the mean EES between age groups $(\mathrm{p}<0.05)$, for occupants who had sustained AIS 2+ and AIS 3+ level chest injuries. Table 2 also shows the mean EES for the weighted RAIDS data sample collected between 2013 and 2018. Similar to CCIS data, crash speeds were higher with higher injury severity. The mean EES for AIS 2+ chest injured elderly front seat occupants (39.1 km/h, n=68) was less than that for young (51.2 km/h, $\mathrm{n}=15)$ and middle aged (40.2 km/h, $\mathrm{n}=39)$ occupants. The mean EES of AIS $3+$ chest injured elderly occupants (40.3 km/h, n=46) was less than for the young (70.8 km/h, n=4) and middle-aged (44.9 km/h, $n=19$ ) occupants. Although the small number of young occupants with AIS 3+ injury limits the accuracy of the mean EES value.

Type of AIS 2+ chest injury: There were 427 AIS 2+ chest injuries sustained (Table A 3, Appendix). Some of the occupants had more than one AIS 2+ chest injury. If an occupant sustained skeletal fracture and pulmonary complications such as pneumothorax, haemothorax, haemo-pneumothorax, and flail chest, then the injuries were counted as a single injury. Skeletal injuries were the most common type of AIS 2+ chest injuries, followed by intrathoracic organ and vessel injuries. The recorded numbers of injuries to the thoracic skeletal, organ and 
vessel were 328 (77\%), 88 (20\%) and 11 (3\%) respectively. Sternum fractures made up a large proportion of all AIS 2+ chest injury occurring in 209 occupants. Multiple rib fracture with more than 4 fractured ribs was the second most common type of skeletal chest injury occurring in 87 occupants. 26 occupants had fractures to 2 or 3 ribs. Injury to the lungs was the most common type of intrathoracic organ injury, 44 such injuries were recorded in the sample. Lung contusion was the most common type of lung injury $(\mathrm{n}=42)$ and was mostly rated at AIS 3 or 4 levels. Pneumothorax $(n=9)$ was the second most common type of intra-thoracic organ injury followed by injury to the diaphragm $(n=8)$ and pericardium $(n=7)$. Other intrathoracic organ injuries occurred for fewer occupants. Vessel injuries were most likely to be rated at AIS 4+ and occurred more sporadically. Injury to the aorta $(n=9)$ was the most common type of vessel injury.

Injury causation for AIS 2+ chest injuries: Of 338 occupants with AIS 2+ chest injury, 76\% (n=257) had one or more chest injuries due to the occupant loading the seat belt alone. For a further $15 \%(n=52)$ of occupants, injury was caused by impact with the steering wheel. In $5 \%(n=15)$ of occupants, AIS 2+ chest injury was entirely due to impact with other components such as the airbag, side door, and vehicle interior panels. 8 occupants had chest injuries caused by a combination of loading. The components associated with AIS 2+ chest injury for the remaining 6 occupants were not known.

Injury causation for all AIS 2+ chest skeletal injury: Restraining loads transmitted via the seat belt were the single major cause of injury for all skeletal fractures. $79 \%(n=259)$ of all skeletal fractures were caused by this loading, $17 \%(n=55)$ were from steering wheel impact and $4 \%(n=14)$ from other sources. Belt loads were the cause of injury for $91 \%(n=190)$ of the sternum fractures, $54 \%(n=14)$ of the $2-3$ rib fractures and $61 \%(n=53)$ of 4 or more rib fractures. There was no difference in the proportion of steering wheel impact (50\%) to seat belt loading (50\%) as a source of injury for single rib fractures (Figure 2).

Rate of AIS 2+ chest skeletal fracture by age: The rate of sternum and rib fracture for all front seat occupants who had sustained a chest injury $(n=2211)$ is shown in Figure 3. In total, 328 skeletal fractures were reported in the sample. Some of the occupants had both sternum and rib fractures. Sternum and rib fracture combinations were most common with the elderly occupants and least common with the younger occupants. $16 \%$ ( $n=65)$ of the elderly occupants had sustained sternum fracture compared to $13 \%(n=123)$ for middle aged and $2 \%(n=21)$ for younger occupants. $12 \%(n=46)$ of the elderly occupants had reported with 4 or more rib fractures, which was the second most common type of skeletal fracture among the elderly occupants, compared to $3 \%$ ( $n=29$ ) for middle-aged and $1 \%(\mathrm{n}=12)$ for younger occupants.

Injured intra-thoracic organs and fractured ribs: Figure 4 shows a strong association between organ injury and number of rib fractures. Almost $60 \%(n=52)$ of the intra-thoracic organ injuries (not including pneumothorax and haemothorax) were associated with 2 or more rib fractures. The majority of lung injuries $(56 \%, n=25)$ were associated with 2 or more rib fractures.

\section{DISCUSSION}

This study examined the factors associated with belted front seat occupant chest injury in real frontal impacts involving cars complying with ECE R94. The data sample used was representative of tow away injury crashes 
in the UK. The study suggested that intrusion control is generally good, since $91 \%$ of occupants had experienced facia intrusion below $3 \mathrm{~cm}$. Only 2\% of occupants in the data sample had sustained AIS 2+ head injury, indicating that modern restraints offer good protection for the head. This concurs with earlier real-world studies (Frampton et al. 2006: Kirk et al. 2002). There were few neck injuries rated at the AIS $3+$ level, suggesting that serious and life-threatening neck injuries are also not common in frontal crashes. Of all body regions, the chest was of most concern. The chest was the most often injured body region at AIS 2+, 3+ and 4+ injury levels. A relatively high frequency of severe chest injury in frontal impacts is reported by several authors (Kitagawa \& Yasuki 2013; Ridella et al. 2005; Brumbelow \& Zuby 2009). European studies on frontal impact thoracic injury have been conducted in recent times (Newstead et al. 2006; Carroll et al. 2009a). However, the Newstead et al study was only able to access data up to 2005, whilst this current study was able to access UK CCIS data to 2010 and UK RAIDS data to 2018. The Carroll et al study analysed UK CCIS data to 2009 but the data analysis was unweighted. The current study was able to weight the data which provided a closer approximation to the tow away population and a larger data set for analysis.

Crash severity exposure was similar between different occupant age groups, yet the occupant groups of young, middle-aged and elderly occupants were very different in terms of chest injury risk. The rates of AIS $2+$ and AIS 3+ chest injuries were highest among elderly occupants and lowest among the young occupants. Moreover, elderly occupants tended to sustain their severe chest injuries in lower energy impacts compared to the other two occupant groups. This is in agreement with previous studies (Augenstein et al. 2005; Mertz \& Dalmotas 2007). Younger occupants tended to receive proportionally less AIS 2+ chest injuries even in more severe crashes. In impacts with EES above $50 \mathrm{~km} / \mathrm{h}$, only $24 \%$ of the younger front seat occupants had sustained AIS 2+ chest injuries, whereas the corresponding rate of injury for middle-aged and older occupants were $37 \%$ and $53 \%$ respectively. The implication here is that young occupants are quite well protected compared to other age groups. The overall results highlight an on-going concern about protection for the elderly in relatively low severity crashes. AIS 2+ and 3+ chest injuries to elderly occupants were sustained with little intrusion and at relatively low mean crash severities (31 km/h for AIS 2+ and $36 \mathrm{~km} / \mathrm{h}$ for AIS 3+). Even in the most recent cars from the 2013-2018 dataset, the mean crash severities were low (39 km/h for AIS 2+ and $40 \mathrm{~km} / \mathrm{h}$ for AIS 3+). Frampton and Mackay, in 1994, found similar results in pre- R94/EuroNCAP vehicles without airbags, pretensioners or load limiters. Half of their belted front seat passenger fatalities had sustained impacts below 50 $\mathrm{km} / \mathrm{h}$ with little passenger compartment intrusion.

Crash severity exposure was similar for both front seating positions, it was also similar between different occupant age groups in each seating position, yet chest injury outcome was very different for drivers and front seat passengers. The front passenger was more often associated with significant chest injury compared to the driver. The rate of chest injury was higher for passengers than for drivers at all levels of severity. At the AIS 2+ level, passengers sustained chest injury at 1.7 times the rate of drivers, and AIS 3+ injury occurred at twice the rate of drivers. Examination of seat occupant factors suggested an explanation. The proportion of elderly occupants in the front passenger seat was higher compared to the driver seat (18\% compared to $12 \%)$. The driver seat had the highest proportion of younger occupants, $52 \%$ were below 40 years of age. Differences in the gender proportion was also observed between the two front seating positions. The majority of drivers were male (63\%), while the majority of front seat passengers were female (67\%). The difference in the injury risk between 
the two seating positions in this study could be due to an overrepresentation of older, female occupants who are generally more susceptible to serious chest injuries than their younger male counterparts. Thoracic injury tolerance as a result of age and gender combinations warrants further research. Such research could aid in the choice of appropriate injury criteria for assessing older occupant safety. Carroll et al. (2009b), also found that front passengers tended to sustain more severe injury than drivers, although their European frontal impact sample was small (20 UK CCIS and 14 German GIDAS cases) and selected to represent the type of frontal crash loading assessed by a EuroNCAP offset test. It could be argued that for comprehensive coverage, full overlap impacts, which are more challenging for restraint load dispersion, could also have been included. The frontal impacts examined in the current study did include all frontal impact types and supports questioning whether, in the real world, restraint systems are better optimised for drivers than for passengers. This is potentially an important consideration and warrants further investigation.

In this study, skeletal injury was the most frequent type of AIS 2+ chest injury. Injuries to intrathoracic organs were the second most frequently occurring AIS 2+ chest injuries followed by injuries to vessels. Skeletal injury mainly comprised of sternum and rib fractures. Sternum fracture, 4 or more fractured ribs and lung contusion were the most frequent injury types. Sternum fractures are usually coded at the AIS 2 level. They are generally less severe when occurring alone and are less likely to cause any further complication. The lungs were by far the most frequently injured intra-thoracic organs. This was followed by the pericardium and the heart. Injuries to vessels were less common in the sample, however, those injuries are mostly rated at the AIS 4+ level, and are life threatening, so should not be disregarded based on a low frequency of occurrence.

The rate of injury for elderly occupants with skeletal injuries (sternum, single rib, 2-3 rib and 4+ rib fractures) was higher than for the other two age groups. Particularly, the difference in the rate of sternum and AIS 4+ rib fractures between elderly and young occupants. However, the higher rate of skeletal injuries to middle aged occupants compared to the young was also notable. Fractures to the ribs and sternum were mainly caused by restraining loads transmitted through the belt, clearly reinforcing the idea that the restraint system performs optimally for young occupants. An observation supported by the result showing how much higher the rates of AIS 2 were for middle aged occupants compared to the young.

This study was also extended to look at the relationship between rib fractures and the occurrence of intrathoracic injuries. With the increase in the number of rib fractures, the risk of pulmonary complications and organ injuries tended to increase, concurring with previous studies (Kent et al. 2008; Thor \& Gabler 2008). To understand the nature of the injury occurrence for the different age groups, the crash severity of such injury types should be further studied. Such analysis could give an association between the crash severity (i.e. magnitude of the force experienced) and the number of rib-intrathoracic injuries. What is important to note is that nearly $40 \%$ of lung contusions occurred with one or no rib fracture. The injury mechanism for this is not clear and deserves further consideration.

This study has highlighted the continuing issues related to chest injury with older occupants in frontal impacts. Particularly in relation to the front passenger seat where a large proportion of the occupants are elderly and female. The major cause of chest injury was identified as restraining loads transmitted to the chest via the seat belt, and in the absence of intrusion, it is suggested that the opportunity exists for restraint system improvements 
to better manage the crash pulse. There are efforts to promote this in European frontal crash test protocols. EuroNCAP introduced a $50 \mathrm{~km} / \mathrm{h}$ full overlap frontal test of the restraint system in 2015 . This includes a belted $5^{\text {th }}$ percentile Hybrid III driver but does not include a dummy on the front passenger seat. European frontal impact compliance testing still does not assess the vehicle restraint system under a high ' $g$ ' scenario. The European Commission is planning to introduce a new frontal test, UNECE R137, in its type approval system from September $1^{\text {st }}$, 2020. This specifies a $50 \mathrm{~km} / \mathrm{h}$, full width rigid barrier impact with driver and passenger $50^{\text {th }}$ and $5^{\text {th }}$ percentile Hybrid III dummies respectively. The introduction of restraint testing for European vehicles is welcome, since offset testing has promoted stiffer and stiffer front crash structures which do not improve crash safety in all conditions. However, results of this study suggest that a $50 \mathrm{~km} / \mathrm{h}$ impact speed may be too high to address the crash conditions where middle aged and elderly occupants sustain AIS 2+ and AIS 3+ chest injuries. Instead, it supports the view that there could be a large target population who might benefit from a low energy restraint test.

Results suggest that age may be more of an issue than gender. They also suggest that an improved dummy thorax should be able to predict rib and sternum fracture, and the risk of lung contusions; and that injury risk values need to be utilised to reflect the biomechanical tolerance of not only the elderly but also those of middleaged occupants. EuroNCAP will shortly introduce the THOR frontal impact dummy, which has improved biofidelity and is capable of utilising age dependent injury risk functions. This may go some way towards encouraging improved chest protection.

If predictions for the demographic shift in populations toward the elderly are correct, this study shows the necessity for safety interventions, through new, possibly adaptable restraint systems to improve chest protection. This is a challenge for single point restraints optimised for specific crash conditions. Evidence for this is clearly visible in cars that perform very well in EuroNCAP offset tests but fare rather worse in full overlap testing. The overall value of the seat belt restraint in reducing serious crash injuries has been verified in countless studies and is not questioned here. Instead, the results suggest there may be an opportunity to improve the efficacy of current systems. What is evident is that the front passenger seating position offers the largest opportunity for developing the restraint system intrinsic compliance needed to reduce chest loads. Too much compliance can reduce occupant protection under certain crash conditions, but an adaptive restraint system concept has shown some promise. Such a system could vary load limiting, pretensioning and airbag deployment according to crash type, occupant type, and seating position, for optimal occupant protection. Several studies have reported that intelligently varying the restraint deployment characteristics by accounting for differences in age related injury tolerance may better manage the restraint forces acting on the chest in frontal crashes (Ekambaram et al. 2015; Hynd et al. 2011; Hardy et al. 2005; Bosch et al. 2005). Ekambaram et al. (2015) showed some promising results when just one component of the restraint system was varied. They estimated the real world injury reduction benefit of adaptive load limiters by applying numerical crash simulations results to a real world crash injury database. They reported that, if the vehicles in their sample were fitted with smart load limiters, the risk of sustaining an AIS $2+$ chest injury could decrease by $5 \%$ and $2.7 \%$ for older and middle-aged front seat occupants respectively. 


\section{ACKNOWLEDGEMENTS}

The project used accident data from the current Road Accident In-depth Studies (RAIDS), which is managed by the Transport Research Laboratory on behalf of the UK’s Department for Transport (DfT), who funded the programme. Furthermore, it used data from the Co-operative Crash Injury Study (CCIS), also managed by the Transport Research Laboratory on behalf of DfT who funded the project along with Autoliv, Ford Motor Company, Nissan Motor Company and Toyota Motor Europe. Previous sponsors of CCIS have included Daimler Chrysler, LAB, Rover Group Ltd, Visteon, Volvo Car Corporation, Daewoo Motor Company Ltd and Honda R\&D Europe (UK) Ltd. Data were collected by teams from the Birmingham Automotive Safety Centre of the University of Birmingham; the Vehicle Safety Research Centre at Loughborough University; the Transport Research Laboratory; and the Vehicle \& Operator Services Agency of the DfT. For further information about the UK collision investigation data, please go to RAIDS@dft.gsi.gov.uk 


\section{References}

Abbreviated Injury Scale 2005. Association for the Advancement of Automotive Medicine

(AAAM). Barrington, Illinois, U.S.A. 2005.

Abbreviated Injury Scale 1990 Revision. Association for the Advancement of Automotive Medicine (AAAM). Des Plaines, Illinois, U.S.A. 1990.

Augenstein, J. Differences in clinical response between the young and the elderly. Proceedings of the Aging and Driving Symposium, Association for the Advancement of Automotive Medicine. 2001.

Australian Bureau of Statistics. Population Projections, Australia 2004- 2101, Canberra, Australia.2006

Bosch M, Brandse J, Lemmen P, Neale M, Couper G, Frampton R. Development and evaluation of Smart Restraints: EC PRISM. In 5 ${ }^{\text {th }}$ European MADYMO User Conference, Cambridge, 2005 September 26 (pp. 62-71).

Brumbelow, Matthew L, David S. Zuby. Impact and injury patterns in frontal crashes of vehicles with good ratings for frontal crash protection. 21st ESV Conference. No. 09-0257. 2009.

Carroll J A. COVER D5 - Main summary report: Matrix of serious thorax injuries by occupant characteristics, impact conditions and restraint type and identification of the important injury mechanisms to be considered in THORAX. THORAX project GA. 2009a.

Carroll J A, Smith S, Adolph T, Eggers A, Hynd D. A comparison between crash test results and real-world accident outcomes in terms of injury mechanisms and occupant characteristics. THORAX project GA. 2009b; 218516.

DaCoTA. European Road Safety Report. Traffic Safety Basic Facts 2011, The Elderly (Aged >64), 2011.

Dejeammes M, Ramet M. Aging process and safety enhancement of car occupants. In Proceedings: International Technical Conference on the Enhanced Safety of Vehicles, vol. 1996, pp. 1189-1196. National Highway Traffic Safety Administration, 1996.

Dellinger AM, Langlois JA, Li G. Fatal crashes among older drivers: decomposition of rates into contributing factors. American Journal of Epidemiology. 2002 Feb 1;155(3):234-41.

Ekambaram K, Frampton R, Bartlett L. Improving the chest protection of elderly occupants in frontal crashes using SMART load limiters. Traffic injury prevention. 2015 Oct 8;16 (sup2):S77-86.

Frampton R, Page M, Thomas P. Factors related to fatal injury in frontal crashes involving European cars. In Annual Proceedings/Association for the Advancement of Automotive Medicine 2006 (Vol. 50, p. 35). Association for the Advancement of Automotive Medicine. 
Frampton RJ, Mackay GM. The Characteristics of Fatal Collisions for Belted Occupants. In SAFETY.

Technical papers from the 25th FISITA Congress, Beijing, 1994, Vol 4. Technical Paper No. 945167 1994.

Hardy R, Watson J, Frampton R, Page M, Zioupos P, Cook R, Kennedy A, Sproston P, Forrester B, Peach S. BOSCOS-Developments and Benefits of a Bone Scanning System. In IRCOBI Conference Proceedings Prague, Czech Republic. 2005.

Hassan AM, Hill JR, Parkin S, Mackay GM. Secondary Safety Developments: Some Applications of Field Data. Autotech 1995; ImechE. 1995.

Hynd D, Carroll J, Richards D, Wood R, Goodacre O. Restraint system safety diversity in frontal impact accidents. TRL Published Project. 2011 Nov.

Islam S, Mannering F. Driver aging and its effect on male and female single-vehicle accident injuries: Some additional evidence. Journal of safety Research. 2006 Jan 1;37(3):267-76.

Kent R, Trowbridge M, Lopez-Valdes FJ, Ordoyo RH, Segui-Gomez M. How many people are injured and killed as a result of aging? Frailty, fragility, and the elderly risk-exposure trade off assessed via a risk saturation model. InAnnals of Advances in Automotive Medicine/Annual Scientific Conference 2009 Oct 5 (Vol. 53, p. 41). Association for the Advancement of Automotive Medicine.

Kent R, Sang-Hyun L, Darvish K, Wang S. Structural and material changes in the aging thorax and their role in crash protection for older occupants. Stapp car Crash journal. 2005 Nov 1;49:231.

Kent R, William W, Ola B. Fatality risk and the presence of rib fractures. In Annals of Advances in Automotive Medicine/Annual Scientific Conference, vol. 52, p. 73. Association for the Advancement of Automotive Medicine, 2008.

Kirk A, Frampton RJ, Thomas PD. An Evaluation of airbag benefits/disbenefits in European vehicles-a combined statistical and case study. In IRCOBI Conference Proceedings, Munich, 18-20 September., 2002.

Kitagawa Y, Tsuyoshi Y. Correlation among seat belt load, chest deflection, rib fracture and internal organ strain in frontal collisions with human body finite element models. In IRCOBI Conference Proceedings, no. IRC-13-36. 2013.

Lenard J, Hurley B, Thomas PD. The accuracy of CRASH3 for calculating collision severity in modern European cars. 1998.

Mackay GM, Ashton SJ, Galer MD, Thomas PD. The methodology of in-depth studies of car crashes in Britain. No. 850556. SAE Technical Paper, 1985. 
Mertz HJ, Dalmotas DJ. Effects of shoulder belt limit forces on adult thoracic protection in frontal collisions.

No. 2007-22-0015. SAE Technical Paper, 2007.

Morris A, Welsh R, Hassan A. Requirements for the crash protection of older vehicle passengers. In Annual Proceedings/Association for the Advancement of Automotive Medicine, vol. 47, p. 165. Association for the Advancement of Automotive Medicine, 2003.

Newstead S, Delaney A, Cameron M. Use of in-depth data in comparing EuroNCAP and real-world crash results. SARAC II (Quality criteria for the safety assessment of cars based on real-world crashes) Report of subtask 2.3. 2006. Available from the EC internet site:

http://ec.europa.eu/transport/road/publications/doc/sarac2_2.3.pdf.

Oxley J, Langford J, Charlton J. The safe mobility of older drivers: a challenge for urban road designers. Journal of Transport Geography. 2010 Sep 1;18(5):642-8.

Ridella SA, McCann MJ, Turnbull RC, Bayley GS. Development of restraint systems with considerations for equality of injury risk. In Proceedings of the 19th international technical conference on the Enhanced Safety of Vehicles (ESV), 6-9 June, 2005, Washington, DC, USA. 2005.

Ridella SA, Rupp JD, Poland K. Age-related differences in AIS 3+ crash injury risk, types, causation and mechanisms. In IRCOBI Conference Proceedings, vol. 2012. 2012.

Thor CP, Gabler HC. The relationship between thoracic organ injuries and associated rib fractures. LUNG 339 (2008): 246.

Welsh R, Morris A, Hassan A, Charlton J. Crash characteristics and injury outcomes for older passenger car occupants. Transportation research part F: traffic psychology and behaviour 9, no. 5 (2006): 322-334.

Zaidi A. Features and challenges of population ageing: The European perspective. Policy Brief March (1) (2008). 
Table 1 Injury Severity Rate for Each Body Region

\begin{tabular}{ccccccc}
\hline & Head & Neck & Chest & Abdomen & $\begin{array}{c}\text { Epper } \\
\text { Lx }\end{array}$ & $\begin{array}{c}\text { Eower } \\
\text { Ex. }\end{array}$ \\
\hline AIS 2+ & $1.9 \%$ & $1.1 \%$ & $6.5 \%$ & $2.3 \%$ & $6.3 \%$ & $5.1 \%$ \\
& $(\mathrm{n}=98)$ & $(\mathrm{n}=59)$ & $(\mathrm{n}=338)$ & $(\mathrm{n}=122)$ & $(\mathrm{n}=331)$ & $(\mathrm{n}=268)$ \\
AIS 3+ & $(\mathrm{n}=47)$ & $(\mathrm{n}=8)$ & $(\mathrm{n}=133)$ & $(\mathrm{n}=39)$ & $(\mathrm{n}=49)$ & $(\mathrm{n}=116)$ \\
& $0.4 \%$ & $0.0 \%$ & $1.0 \%$ & $0.2 \%$ & $0.0 \%$ & $0.0 \%$ \\
AIS 4+ & $(\mathrm{n}=24)$ & $(\mathrm{n}=1)$ & $(\mathrm{n}=52)$ & $(\mathrm{n}=8)$ & $(\mathrm{n}=0)$ & $(\mathrm{n}=0)$ \\
\hline
\end{tabular}

Table 2 Mean EES of Chest Injured Occupants by Age Group

\begin{tabular}{cccc}
\hline & \multicolumn{3}{c}{ Mean EES (km/h) } \\
\cline { 2 - 4 } & Young & Mid & Elderly \\
\hline Chest AIS 2+ & $45.2(51.2)$ & $32.1(40.2)$ & $30.8(39.1)$ \\
Chest AIS 3+ & $49.9(70.8)$ & $42.6(44.9)$ & $36.0(40.3)$ \\
\hline
\end{tabular}

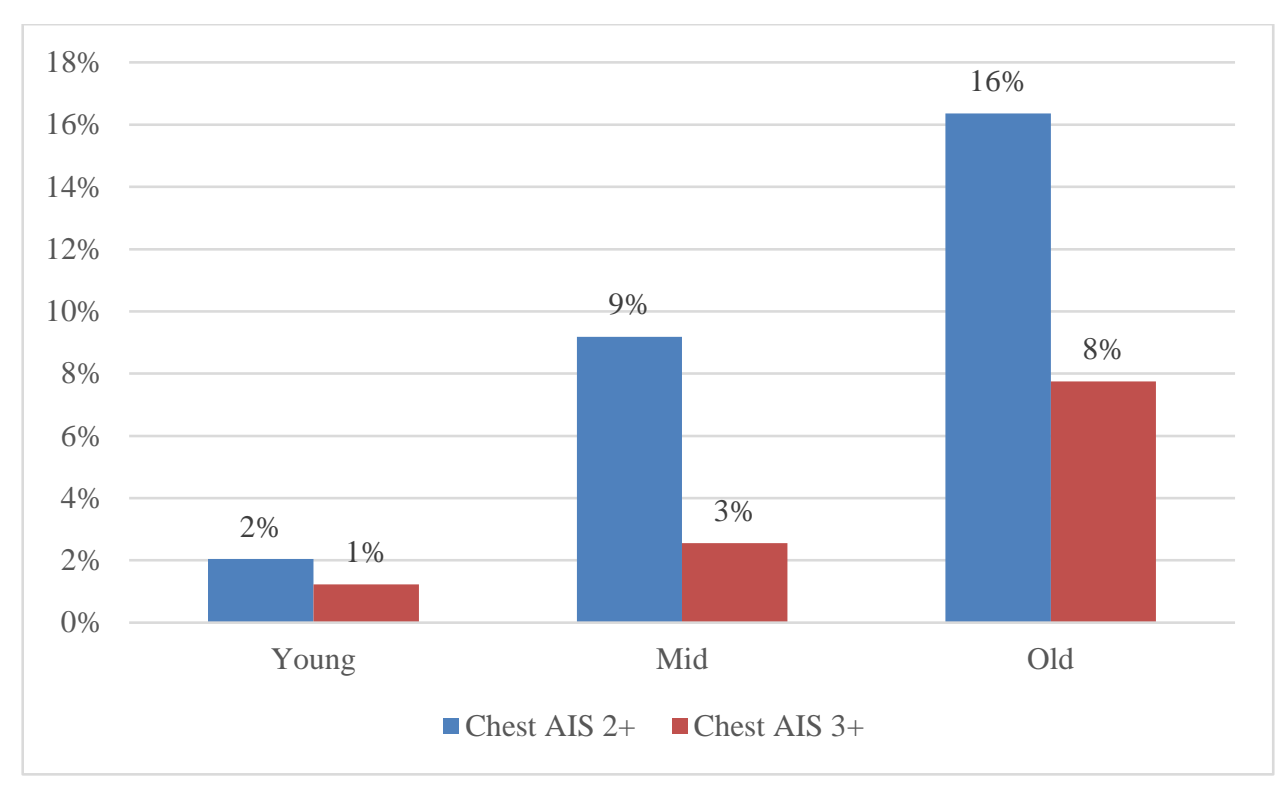

Figure 1 Chest Injury Severity Rate by Age 


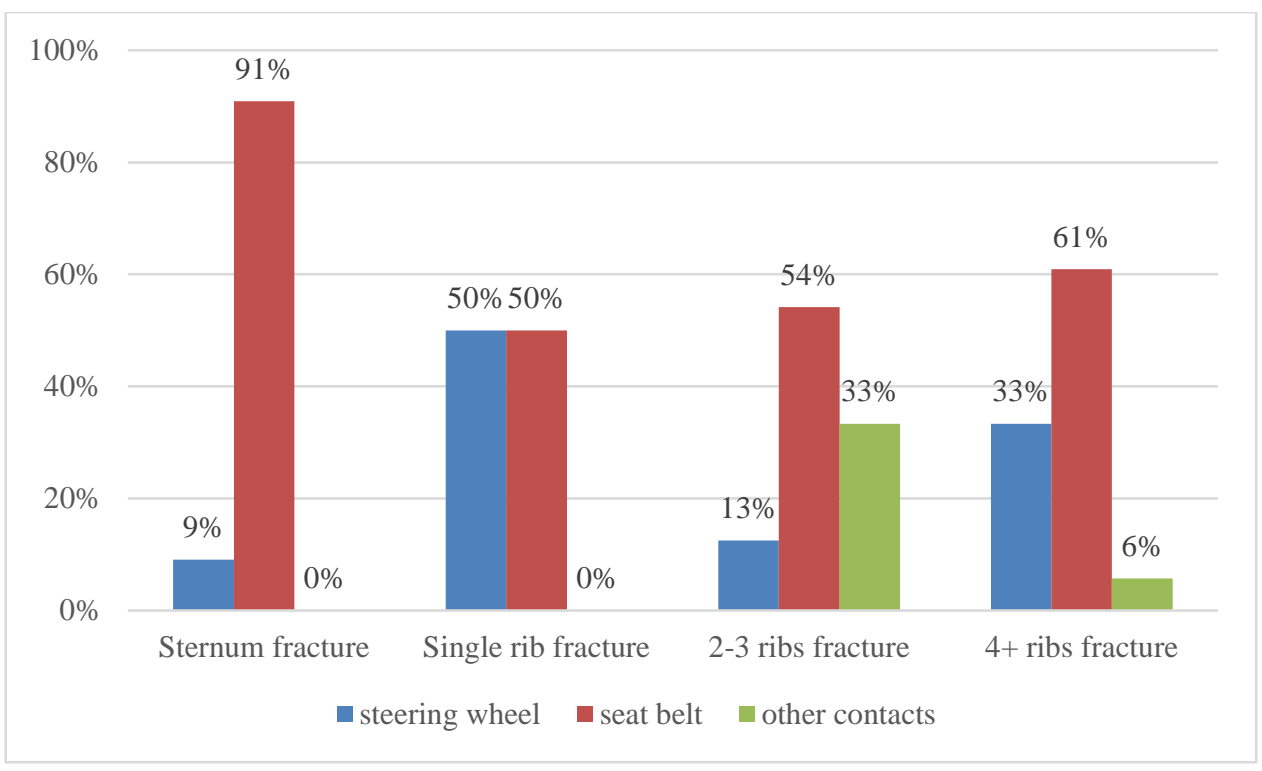

Figure 2 Component Associated with AIS2+ Skeletal Injury

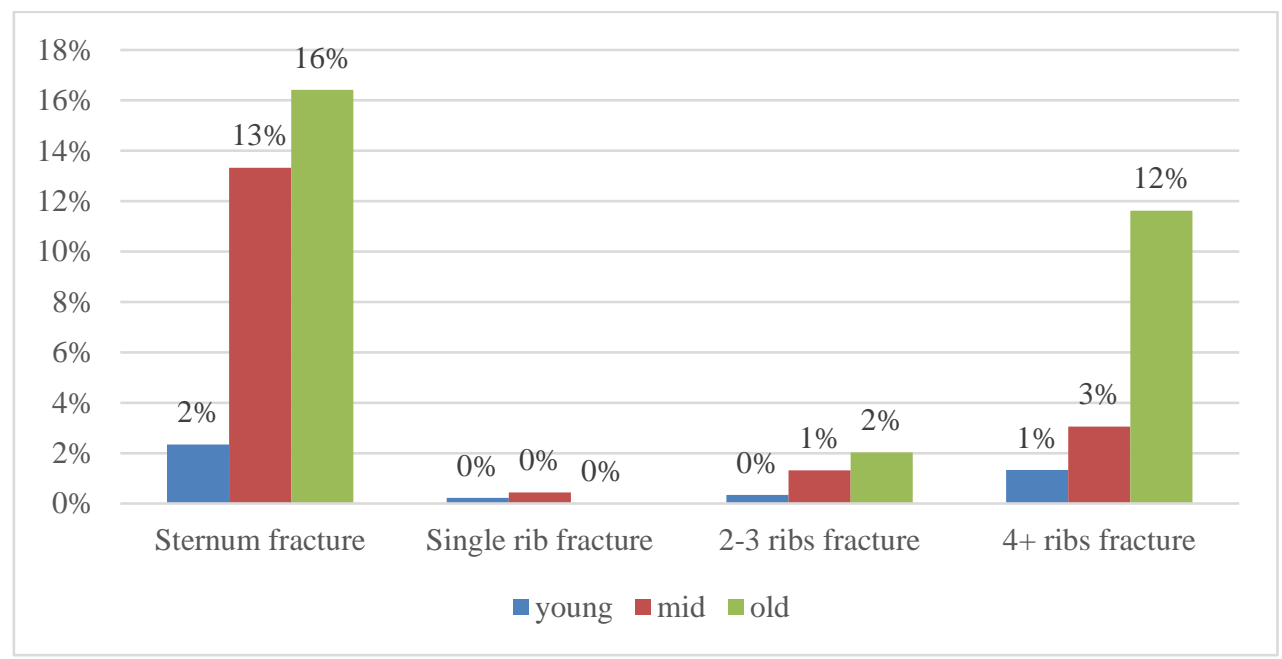

Figure 3 Rate of Chest Skeletal Fracture by Age

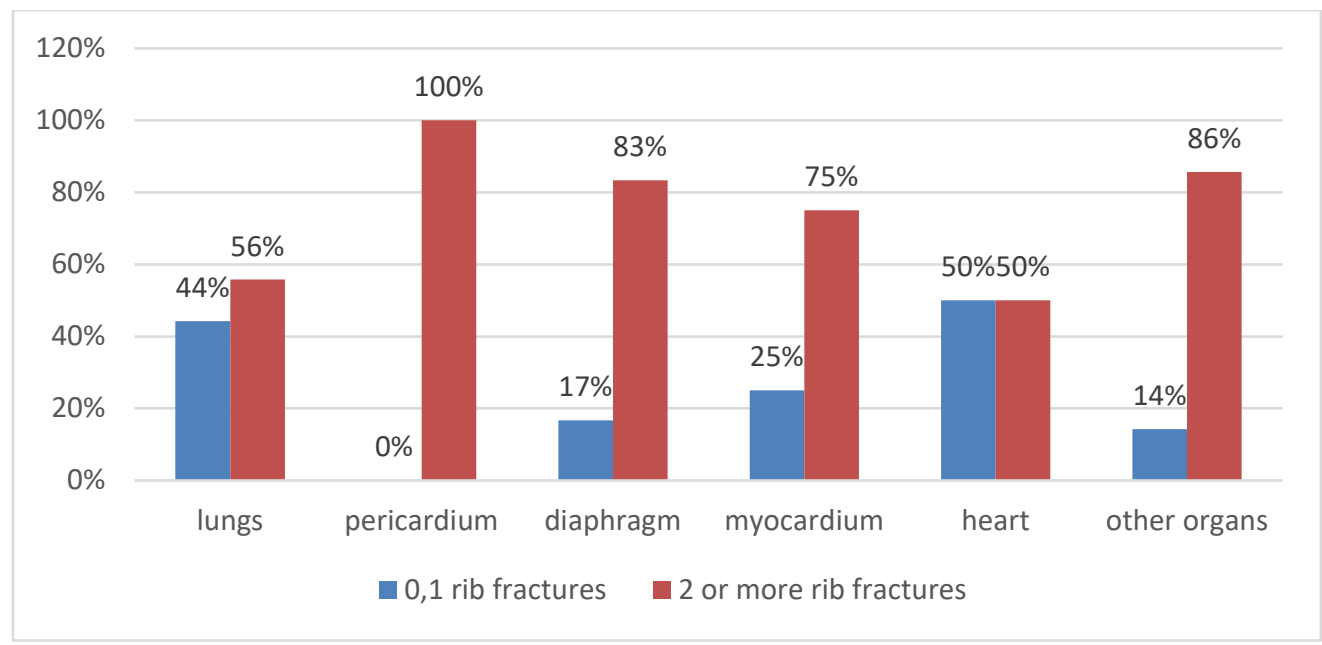

Figure 4 Association of Chest Organ Injury with Number of Rib Fractures 


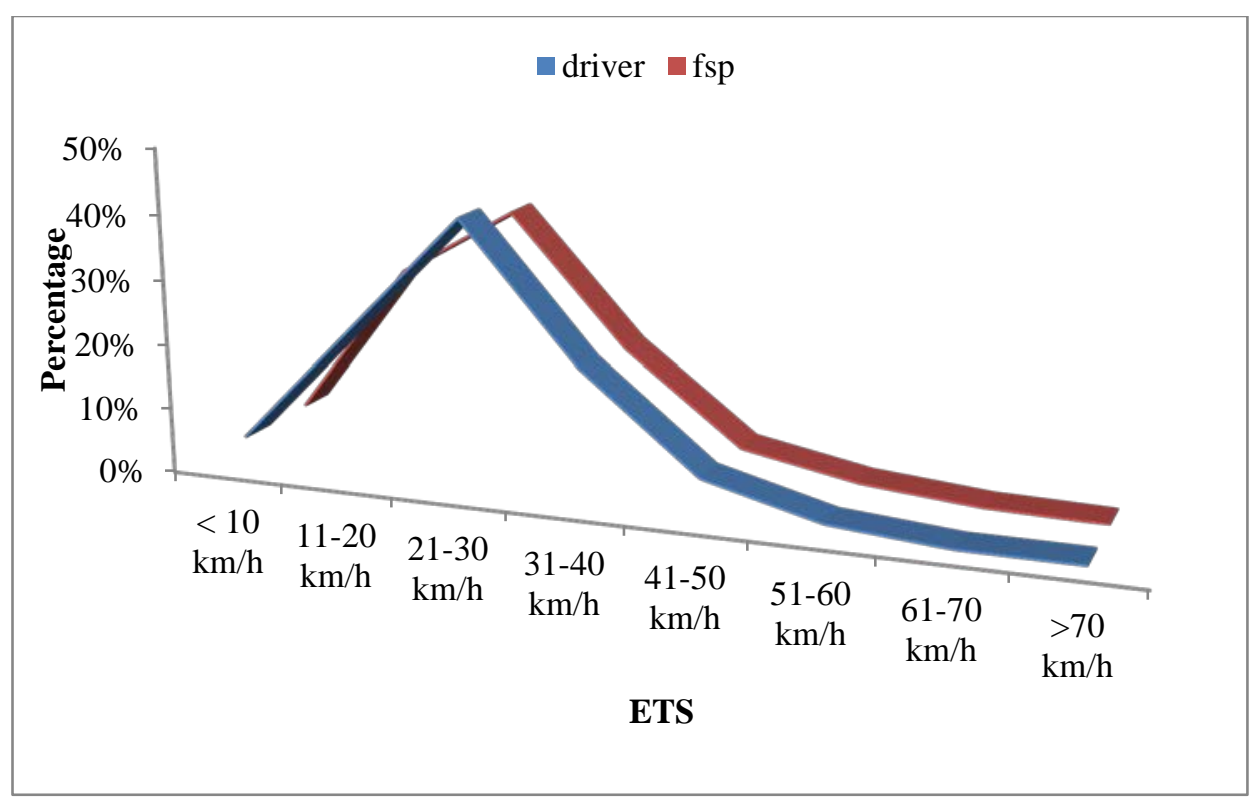

Figure A 1 EES Distributions by Seating Position

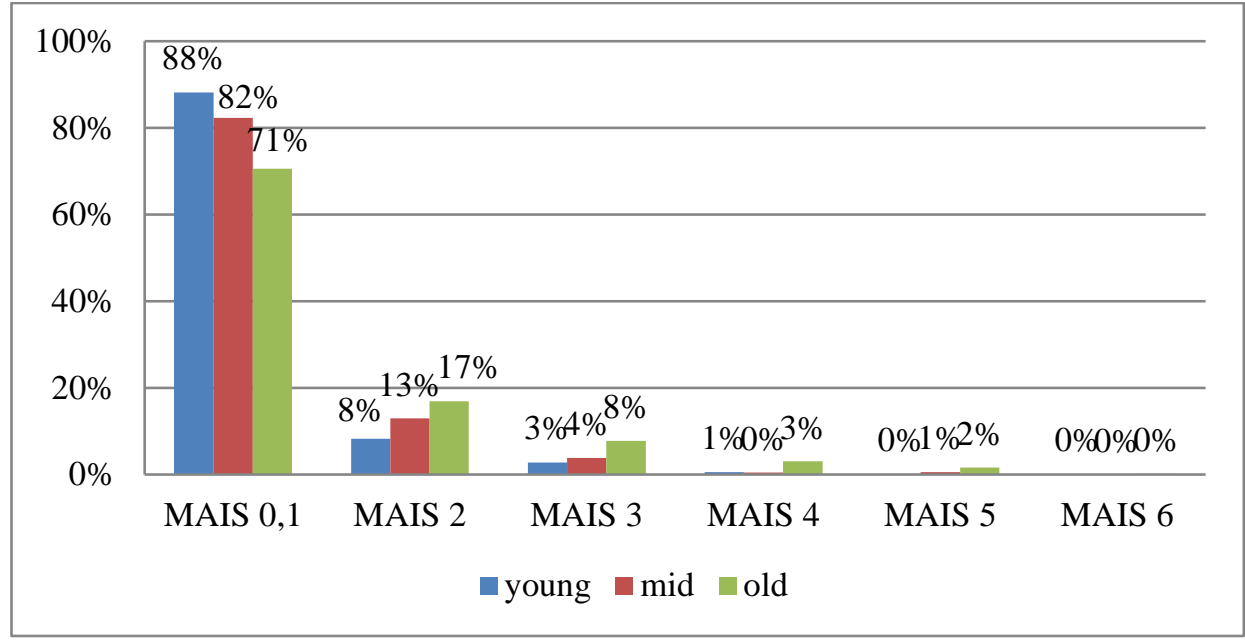

Figure A 2 MAIS by Age Group

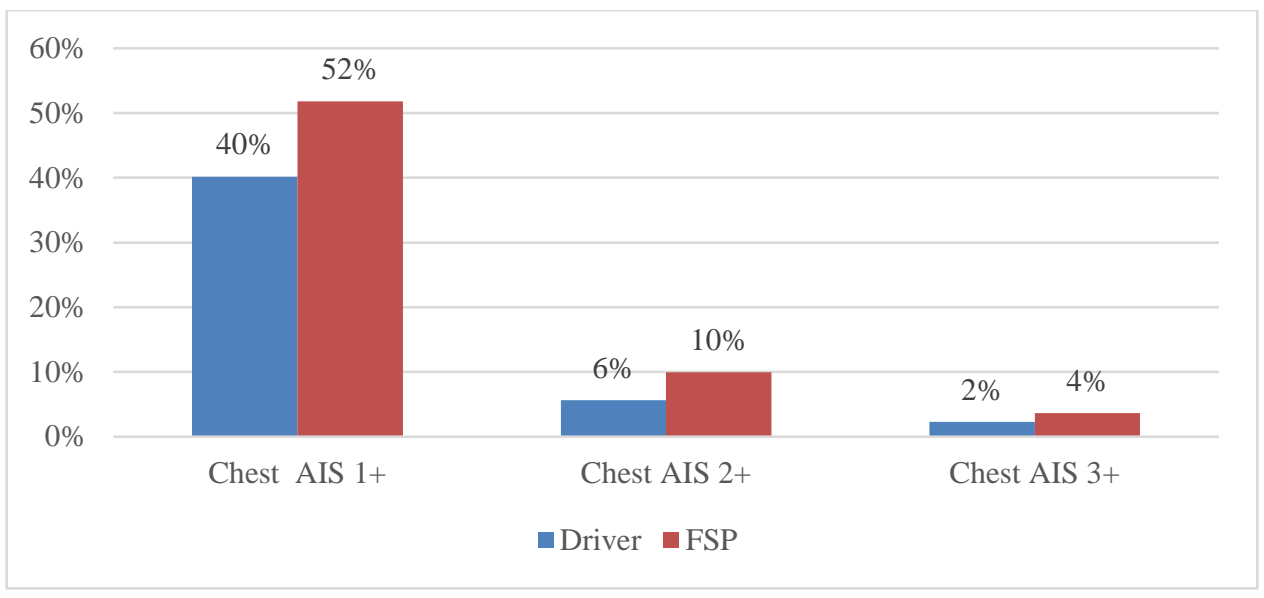

Figure A 3 Chest Injury Severity by Seating Position 
Table A 1 Mean ETS by Seating Position and Occupant Age

\begin{tabular}{|c|c|c|c|}
\hline \multirow{2}{*}{$\begin{array}{l}\text { Seating } \\
\text { Position }\end{array}$} & \multicolumn{3}{|c|}{ Mean ETS $(\mathbf{k m} / \mathrm{h})$} \\
\hline & $\begin{array}{c}<40 \\
\text { (Young) }\end{array}$ & $\begin{array}{c}\text { 40-64 } \\
\text { (Middle-aged) }\end{array}$ & $\begin{array}{c}65+ \\
\text { (Old) }\end{array}$ \\
\hline Driver & 26.68 & 26.20 & 25.88 \\
\hline FSP & 26.13 & 25.16 & 25.24 \\
\hline
\end{tabular}

Table A 2 MAIS for Front Seat Occupants

\begin{tabular}{cccc}
\hline \multirow{2}{*}{$\begin{array}{c}\text { Injury } \\
\text { Severity }\end{array}$} & \multicolumn{3}{c}{ Front Seating Position } \\
\cline { 2 - 4 } & Driver & Front passenger & All occupants \\
\hline MAIS 0,1 & $\begin{array}{c}85.2 \% \\
(\mathrm{n}=3666)\end{array}$ & $\begin{array}{c}77.0 \% \\
(\mathrm{n}=718)\end{array}$ & $\begin{array}{c}83.8 \% \\
(\mathrm{n}=4384)\end{array}$ \\
MAIS 2 & $9.8 \%$ & $16.7 \%$ & $11.0 \%$ \\
& $(\mathrm{n}=422)$ & $(\mathrm{n}=156)$ & $(\mathrm{n}=578)$ \\
MAIS 3+ & $5.0 \%$ & $6.2 \%$ & $5.2 \%$ \\
& $(\mathrm{n}=213)$ & $(\mathrm{n}=59)$ & $(\mathrm{n}=272)$ \\
\hline
\end{tabular}


Table A 3 List of AIS 2+ Chest Injury

\begin{tabular}{|c|c|c|}
\hline Injury Area & \multicolumn{2}{|l|}{ Injury Description } \\
\hline \multirow{14}{*}{ Skeletal Injury (328) } & \multirow[b]{2}{*}{ Single rib fracture (6) } & pneumothorax (5) \\
\hline & & haemothorax (1) \\
\hline & \multirow{4}{*}{$2-3$ ribs fracture (26) } & Stable chest (13) \\
\hline & & pneumothorax (7) \\
\hline & & haemothorax (3) \\
\hline & & haemo-pneumothorax (3) \\
\hline & \multirow{5}{*}{$4+$ ribs fracture (87) } & stable chest (42) \\
\hline & & pneumothorax (7) \\
\hline & & haemothorax (16) \\
\hline & & haemo-pneumothorax (13) \\
\hline & & flail chest (9) \\
\hline & \multirow{3}{*}{ Sternum fracture (209) } & stable chest (200) \\
\hline & & pneumothorax (8) \\
\hline & & haemothorax (1) \\
\hline \multirow{23}{*}{ Organ Injury (88) } & \multicolumn{2}{|l|}{ Pneumothorax (9) } \\
\hline & \multicolumn{2}{|l|}{ Haemothorax (3) } \\
\hline & Pneumomediastinum (1) & \\
\hline & & laceration (2) \\
\hline & Lung (44) & contusion (42) \\
\hline & & tear (1) \\
\hline & Pleural cavity/ sac (2) & laceration (1) \\
\hline & Parietal pleura laceration (1) & \\
\hline & & contusion (2) \\
\hline & & rupture (1) \\
\hline & Pericardium (7) & disruption (1) \\
\hline & & haemorrhage (3) \\
\hline & & tear (2) \\
\hline & Myocardial (4) & contusion (2) \\
\hline & Heart contusion (3) & \\
\hline & & tear (2) \\
\hline & Atrium (3) & laceration (1) \\
\hline & Ventricle disruption (1) & \\
\hline & & tear (3) \\
\hline & Diaphragm (8) & laceration (2) \\
\hline & & rupture (3) \\
\hline & Oesophagus tear (1) & \\
\hline & Chordae tendineae rupture (1) & \\
\hline & & laceration (3) \\
\hline & Aorta (9) & rupture (1) \\
\hline Vessel Injury (11) & & transection (5) \\
\hline & Venacava avulsion (1) & \\
\hline & Subclavian artery rupture (1) & \\
\hline
\end{tabular}

